\title{
On the Avoidance Phenomenon in Writing
}

\author{
Xiu Yu \\ Qingdao University of Science \& Technology, Qingdao, China
}

\begin{abstract}
The Avoidance phenomenon is a negative method used by learners who are reluctant to take risks in the process of learning language. For a long time, it is regarded as a kind of learning strategy which has been misused greatly and has hindered the improvement of language learning efficiency. Therefore, through the analysis of English major students' various kinds of avoidance in writing, this article advocates that corresponding measures should be taken to prevent or reduce the occurrence of this phenomenon in English writing teaching.
\end{abstract}

Index Terms — avoidance phenomenon, writing, avoidance in vocabulary, avoidance in grammar

\section{INTRODUCTION}

In English major writing teaching practice, the author found that the composition of many students often has few grammar mistakes, but the whole writing uses simple vocabulary and sentence patterns, which is not parallel to their English. The main reason that leads to this phenomenon is that some students are afraid of making mistakes and losing face, but at the same time, they want to achieve the purpose of communication. Therefore, they avoid using the language and structure that they are less familiar or uncertain about. And the above mentioned phenomenon is called "avoidance" in language.

By analyzing the vocabulary and grammatical avoidance in compositions of English majors, this paper aims to explore the solutions of the avoidance phenomenon from different aspects.

\section{TheORETICAL StUdy OF AVOIDANCE}

The avoidance phenomenon is first put forward by Schachter (1974) in the study of English learners whose mother tongue are different when they are handling the restrictive attributive clauses. According to her, when the second language learners are facing with language difficulties, the avoidance phenomenon will occur because they tend to give up the use of certain words or rules so as to obtain the accuracy of language.

Avoidance is very common in second language acqusition. Thus the detailed information about this phenomenon will be analyzed in the following part.

\section{The AVoidance PHenOMENON In ENGLISH WRITING}

\section{A. Avoidance in Vocabulary}

The avoidance of English major students in vocabulary is mainly manifested in the following four aspects:

1. Use superordinate and general words

In English, superordinate and general words denote large classes or broad areas, actions or qualities. Specific words indicate individual objects, actions or qualities that compose classes or areas (Wang, 2003).

Generally speaking, in English major students' writing, they tend to use superordinate and more general words instead of subordinate or more specific words. Example 1:

There is a small garden in front of my grandpa's house. And he is very good at raising plants and flowers. Some of the plants were very small at the beginning, but now they are large and very beautiful. And there are a lot of colorful flowers inside, white, red, pink, yellow and so on. They not only look pretty but also smell good. My grandpa devotes a lot of time to his garden. Every morning and evening I see him taking care of his plants and flowers like little children. All our friends love to come to his garden to see the beautiful world that my grandpa has made.

From example 1, it can be clearly seen that the superordinate word "flower" is commonly used rather than some subordinate words such as "tulip", "rose", "violet", etc.

Although both general and specific words are useful, a student learning to write should make an effort to master specific words wherever possible because specific words help to make writing more informative, impressive and effective.

For instance, when students want to describe a man that is "good", they can use more specific words such as "generous, selfless, considerate, sympathetic" and so on. If the food is "good", words like "tasty, appetizing, nourishing" are more vivid.

2. Use synonyms

English is rich in synonyms. But there are in fact few or no exact synonyms because the so-called synonyms often have subtle differences of meaning. Synonyms can be different in connotation, stylistic level, the degree of emphasis, 
emotional coloring and collocation, etc. For instance, "eagle" and "hawk" may seem identical to us Chinese, but in English eagle is a bird that soars high and thus sees far, but to "have an eagle eye" means to have excellent vision; while hawk, a bird of prey, symbolizes harshness, thus people call the hard-line politician "the hawks". Then "dove" and "pigeon" may seem to us the same thing, but people say "peace dove" instead of "peace pigeon". To us Chinese, "dumb" and "mute" may mean the same thing; yet "dumb" conveys a negative meaning of not being wise, so people say "the deaf and mute school" but never "the deaf and dumb school". Furthermore, "statesman" and "politician" have the same denotative meaning — one who is skilled in the science of government or politics. In their connotative meaning, however, they are quite different. "statesman" is a complimentary term, meaning "a person with wisdom and skill in managing the affairs of the state"; "politician" is a deragatory term, a term of contempt, implying "a person who is in politics merely for personal gain, and schemes for self-interest". Therefore, people refer to the government leader whom they respect as a statesman, but they call the government official whom they oppose and despise a politician (Wang, 2003).

When the students write their articles, they often can not find some specific and appropriate words immediately. At that time, they will try their best to use a synonym to meet the demands of communication. After that, the sentences they write can always cause confusion or ambiguity.

Example 2: His hard work is going to show consequence.

In this sentence, "consequence" often expresses a derogatory sense. However, the meaning of the sentence does not accord with the meaning that the author want to convey, so people can use the neutral word "results" instead.

Example 3: Look at that lovely tiny boy.

In this example, "tiny" should be replaced by the word "little" because "little" implies the feeling of fondness which means attractively small. On the contrary, "tiny" means something that is extremely small and sometimes abnormal.

Example 4: This is a peace-loving country.

Country, nation, state and land are synonyms. However, they are different in connotation. "Country" means an area of land and its population and government, such as an island country. "Nation" emphasizes "the people of a country" such as a peace-loving nation. "State" usually refers to the government or political organization of a country, that is "state organs". "Land" is similar to "country", but it is less precise and more literary and emotive. For instance, "I love my native land" (Ding, 1994).

Mark Twain once has shown very vividly the importance of choosing the exact word: "Use the right word, not the second cousin" or "The difference between the right and the almost right word is the difference between lightning and the lightning bug." According the above-mentioned examples, we can draw the conclusion that if students want to write more effectively, they must be very sensitive to the shades of meaning between synonyms and choose the right word that can appropriately express what they are willing to convey.

3. The negative transfer of native language

In the process of writing, the negative transfer of native language is another reason to cause avoidance. For example, being influenced by Chinese, the students usually use "give him some color to see" to express the meaning of "teach sb. a lesson".

Example 5:

Internet is a double-edged sword. On the one hand, it makes people's life easier, convenient and colorful. On the other hand, it brings disadvantageous effect. (a) Let me give you several my own experiences. As people know, internet in fact is a gigantic database that stores the worldwide information. When facing with these multiple choices, I can hardly devote myself to one thing. For example, (b) every time when I get ready to find an English video to improve my level in listening, there are some irrelevant or worthless news distracted my attention. So my time was finally used for browsing some web pages aimlessly.

Obviously, sentences (a) and (b) are negative transfer of Chinese to English. So the two sentences should be revised as "Let me share my own experience with you." And "every time when I get ready to find an English video to improve my listening".

4. Paraphrase and rephrase

Paraphrase and rephrase is also a way of avoidance commonly used by English major students. When they can not express a certain word, the students tend to convey their idea in a roundabout way so as to achieve the purpose of communication. As in the sentence "Arts Festival is a good platform for the students to show themselves", when the students don't know how to express "platform", they may use the following way of expression: Arts Festival is a good way for students to show themselves.

\section{B. Avoidance in Grammar}

\section{Avoid passive voice}

The structure of the passive voice in English is "be + the past participle". Since the form of past participle is further divided into regular changes and irregular changes, and the passive voice is often combined with a variety of tenses, which undoubtedly increases the difficulty of communication. To avoid errors, students tend to use the active sentences, and avoid the use of passive sentences, such as in the following sentences, students are more willing to use sentence (a) instead of sentence (b).

(a). He wanted his wife to wash his clothes at once. 
(b). He wanted his clothes to be washed at once.

(a). They has lost the battle.

(b). The battle has been lost.

Although generally the active voice is acceptable because it is precise and direct, sometimes the passive voice is more impressive than the active, as in the following: When the doer of the action is not important as "The desks and chairs in this room should be more reasonably arranged" Or when the agent is unknown or needs to be emphasized: "In this war, millions of people were driven from their hometown", "This novel was written by William Shakespeare", etc.

From the above examples, it can be seen that passive voice is an important means to achieve effective expression of people's thoughts. Hence, students should endeavor to make full use of it.

2. Avoid long or complex sentences

In writing, the sentence patterns of English major students are generally simple sentences, such as "subject + predicate + object" structure or "subject + verb + complement" structure, and they avoid using long or complex sentences. If all the sentences in a piece of writing are of the same structure and of similar length, it will be monotonous and boring, and then the writing is less effective and impressive. In daily writing, teachers can solve this problem by means of sentence combining practice to improve students' writing style, such as:

(a). The Wuyi Mountains are noted as the most picturesque area in Southeast China.

(b). The Mountains extend more than 500 kilometers along the border of Fujian and Jiangxi.

Sentences (a) and (b) are all subject-first sentences which make the idea diffused, thus they be combined as one: Extending more than 500 kilometers along the border of Fujian and Jiangxi, the Wuyi Mountains are noted as the most picturesque area in Southeast China.

3. Avoid inversion

Inversion is an important grammatical device in English. The proper use of inversion can make the writing more vivid, emphatic and persuasive.

Such as:

(a). Never have I found him in such a good mood.

(b). In this chapter will be found an answer for you.

(c). Quickly and impressively she went to hug her mother.

(d). So much does he worry about his financial position that he can't sleep at night.

However, in practical writing, due to the use of inversion is much more complex than the normal word order, students often avoid using it.

4. Avoid subjunctive mood

As a special verb form in English, the subjunctive mood usually expresses wishes, demands or making statements contrary to fact. For instance:

(a). If I won the game, I would buy the book you want.

(b). If Mary had hurried, she could have caught the bus.

(c). If he were to go abroad, he would go to Italy.

Because of its syntactic and semantic complexity, subjunctive mood is hard to comprehend and master for English learners. Therefore, it's not surprised to find its absence in their writing.

\section{The Cause of Avoidance}

The main reason of avoidance phenomenon is that a lot of English major students don't have a solid language foundation. Some of them don't have enough vocabulary or can not fully grasp certain syntactic rules. In that case, avoidance comes into being. At the same time, the negative transfer of mother tongue and the differences between English and Chinese can also lead to this phenomenon. In addition, if students lack confidence and are afraid of making mistakes in English, they will also make use of avoidance to achieve the purpose of communication. Look at the following example (example 6):

Today I'd like to share with you a topic which is closely related to us. That is "The Enrollment Expansion in Chinese Universities".

With the development of social economy, people proposed new requirements for higher education owing to the bad need of talents. The 16th National Party Congress pointed out that: "We must strive to improve the quality of people to speed up the construction of socialist modernization." The essential step is to fast the pace of the popularity of higher education.

Well, is the enrollment expansion a good thing? In recent years, the continuous expansion of college enrollment, on the one hand, meet people's demand for higher education, while it also caused many problems. We should adopt a scientific attitude to face the problems. And it is conductive to the harmonious development of the universities.

First of all, I want to talk about the advantages. Enrollment expansion gives students more chances to get higher education. A great number of people with higher education will probably promote our economic growth. Next it can improve the quality of people to enhance education and narrow the gap with foreign countries. Finally, it can alleviate the pressure of employment.

Since every coin has two sides, the problems are also very obvious. The first problem is the decline of the education 
quality and the lack of infrastructure. Many students need to solve the accommodation problem themselves. Meanwhile, the lack of teachers leads to a sharp decline of school teaching quality. Therefore, the expansion means the lower standard for students to go to college and it won't bring students good teaching resources. Finally it will lead to the employment issue.

In summary, 21st century is an important strategic period for China's rapid development. Enrollment expansion is a right choice and what we should do is to seek truth from facts and moderate expansion speed so as to create more excellent talents for society!

This short article was written by one of the author's English major student in writing class. When we read it through, we can get that the whole writing want to convey the advantages and disadvantages of the enrollment expansion in Chinese universities. Although it has expressed the main meaning of the topic, it's language is not very effective because it didn't vary the sentence structure and length.

\section{COUntermeasures to Avoidance}

\section{A. Have a Comprehensive Understanding towards Avoidance}

The essence of avoidance phenomenon is a kind of communication strategy. The form of it is to use existing knowledge to avoid that of unknown or uncertain. In many cases, the students who use avoidance strategy in writing can achieve the goal of all or part of the communication. Therefore, on one hand, avoidance strategy has a positive effect, that is the reason why it existed. On the other hand, when students are to avoid writing difficulties, because they do not insist on the use of the expression it should be, part of the communicative purpose are given up. At that time, their written language can not be further improved. So this is the negative aspects of avoidance phenomenon. In writing teaching practice, if teachers don't enhance the study or accumulation of new knowledge and do not induce the students to overcome their language difficulties, avoidance will be frequently used in writing. In that case, the avoidance phenomenon will do harm to the student's language acquisition because too much avoidance may hinder the absorption and assimilation of new language, and thus lead to their English writing cease to advance.

\section{B. To Strengthen the Quantity and Quality of Target Language}

The ultimate reason of avoidance phenomenon is the ineffiency of language input. The students' language information stored in their brain is extremely limited and they have too little accumulation in common vocabulary, sentence pattern and fixed expression. Thus, teachers should increase the quality and the number of target language input, which will be beneficial to enhance the students writing ability and prevent them from using the expression and grammatical structures repeatedly.

\section{Pay Attention to the Way of Error Correction}

Error is inevitable in language learning. Because college students' emotional temperament has been formed, they are inclined to protect themselves and avoid making mistakes. In writing teaching, the teacher should avoid direct and harsh way of error correction. First, teachers should distinguish different types of mistakes, that is, distinguish between global and local error, serious and general error. And the teacher need not correct every mistakes made by students. Second, teachers should adopt flexible ways of correcting errors, such as it can be the spot check by teachers, mutual correction by students or simply self-correction. No matter which way do the teachers use, they should try their best to guide students to find his mistakes and correct by themselves, rather than simply correcting directly.

The following example 7 is a composition written by an English major student on the topic of "My View on College Students' Psychological Problems".

Example 7:

In reality, a lot of college students have varies degree of different psychological problems. There are three common problems among college students.

The most public one is that their psychological endurance of setbacks is weak. When they come into the campus of college, they have a good image for their college life. But when they start and live the college life for a period of time, they find that the college is not like what they looked forward to. For example, maybe their roommates are not so friendly and the class activities are not that colorful. And the gap between the ideal and the reality forms a big reason for college students to have psychological problems.

Another serious mental problem is emotional distress. There are two concentrated expressions. The first is the troubled love. College students love is a common phenomenon. Some students have difficulty in facing and dealing with problems when their relationship is not as usual. The second is friendship trouble. Friendship is an important aspect of people's life. The growing adolescents especially have a strong self-esteem, identity, a sense of need. Everyone's goal and aspiration is different. So when they don't know how to handle these emotional problems, they will feel depressed.

The last problem I want to say is caused by employment. Many college students are under the dual pressure of economy and employment. In general, there is a wrong psychology. Most students recognize only those with genuine talent, to an invincible position in the society in the future. Some students make this pressure into motivation. Therefore, they study hard to improve their competitiveness in the employment market. But there are also many students who are 
difficult to get rid of the wrong psychology of disposable, eventually arouse a sense of depression or low self-esteem.

In modern society, psychological qualities are essential for everyone. As college students, we should have a positive attitude to what we have, what we do and the life we live. You should believe that you are away from psychological problems.

In this example, some words that the student used are not appropriate and effective, and there are also many chinglish sentences in it. During the process of error correction, the teacher firstly underlined the vocabulary and sentences that has problems. Then the teacher asked the author of the composition and another student to revise the composition again. After that, the teacher gave some suggestions to improve the article just as the following:

In reality, a lot of college students have different psychological problems to some degree. In my opinion, there are three reasons that can account for the phenomenon.

Above all, a lot of college students have poor ability to deal with problems and difficulties they encounter. When they first enter into the university, they have high expectation towards campus life. However, when they start to live in the campus for a period of time, they find that college life is different from what they have imaged. For example, maybe their roommates are not so friendly to them and the class activities are not that colorful. Therefore, the great gap between the ideal and the reality will make the college students feel unhappy and then they may have psychological problems.

The second reason is about their emotional distress. It can be caused by two main factors, that is, campus love and friendship. As we all know, campus love now is a common phenomenon among college students. However, some students have difficulty in facing and dealing with problems when they are frustrated in love or their relationship ends. Similarly, when the college students have problems with their friends, because some of the students have strong self-esteem and they don't know how to handle the problems. Thus, they may feel very depressed.

The last problem is caused by employment pressure. Some of the college students regard pressure as a kind of motivation. Therefore, they study hard to improve their competitiveness in the employment market. However, some students waste most of their time and energy to watch movies, play computer games and surf some useless information on internet, which eventually arouse a sense of depression or low self-esteem.

To conclude, as a college student myself, I think we should have a positive attitude and try to be strong enough to face all the challenges in our life, and I also advocate that universities and society can offer more instruction to help the college students solve their psychological problems.

During this error correction process, students can realize their own language problems by themselves, and their motivation can be improved.

\section{Encourage Students to Conquer Psychological Stress and Anxiety}

The reason why some learners avoid using the difficult language points is also related to their psychological stress and anxiety. In daily writing training, the teachers should create relaxed and appropriate language learning environment so as to reduce the students' fear of writing. And students should also be encouraged to have the enthusiasm to use new words and sentence patterns. In that case, students can write more vivid and appropriate language.

\section{CONCLUSION}

In a word, avoidance is a complicated language phenomenon. The above-mentioned avoidance in English major students' writings in vocabulary, grammar and its countermeasures are summarized by the author according to her teaching experience. It is hoped that this article can inspire a number of writing teachers and English major students to improve their teaching and writing.

\section{REFERENCES}

[1] Ding Wangdao. (1994). A Handbook of Writing, Beijing: Foreign Language Teaching and Reaserch Press.

[2] Krashen, S. (1982). Principles and Practice in Second Language Acquisition, Oxford: Pergamon Press.

[3] Ruan Zhoulin. (2000). An Analysis of Avoidance Phenomenon in Second Language Aqusition. Foreign Language Teaching, 1: 19-23.

[4] Schachter, J. (1974). An Error in Error Analysis. Language Learning, 24: 205-214.

[5] Selinker, L. (1972). Interlanguage. International Review of Applied Linguistics, 10: 209-231.

[6] Wang Yulong. (2003). College Guide to Writing, Qingdao: Ocean University of China.

Xiu Yu was born in Qingdao, China in 1980. She received her M.A. degree in linguistics from Ocean University of China, China in 2007.

She is currently a teacher in the School of Foreign Languages, Qingdao University of Science \& Technology, Qingdao, China. Her research interests include psycholinguistics and cognitive linguistics.

Mrs Yu is a member of the linguistic research center in the School of Foreign Languages, Qingdao University of Science \& Technology. 